\title{
Seismic vulnerability of vernacular buildings in urban centres - the case of Vila Real de Santo António
}

\author{
J. Ortega, G. Vasconcelos \& P.B. Lourenço \\ ISISE, Faculty of Engineering, University of Minho, Guimarães, Portugal
}

H. Rodrigues

School of Technology and Management, Polytechnic Institute of Leiria, Portugal

H. Varum

CONSTRUCT-LESE, Faculty of Engineering, University of Porto, Portugal

\begin{abstract}
Following detailed studies of Portuguese vernacular building typologies, this paper deals with buildings located in historical urban centres. An analysis of the history of the urban centre and, in particular, of some vernacular buildings is enhanced. Additionally, a discussion on the influence of changes of the geometry, and on added built volumes to original buildings in the seismic vulnerability of the buildings is also provided.
\end{abstract}

\section{INTRODUCTION}

Vernacular architecture has a distinctly open-ended and spontaneous nature, but it is also mainly characterised by its transformation process. Although there is a strong persistence of the vernacular form, resulting from a characteristic rigid tradition, vernacular constructions are subjected to continuous modifications, because of new needs of the users, or because of changed situations that force it to adapt. The effect of these alterations in the seismic response of the building can be of great importance, because it involves construction aspects such as: (i) the addition of new floors; (ii) the addition of new constructions, built in different materials and poorly attached to the original one; (iii) the enlargement of existing openings, and the opening of new ones; or (iv) the replacement of original structural elements with different ones, e.g. the common replacement of the old wooden floors with reinforced concrete ones.

At an urban level, the effect of these alterations does not affect only the building itself, but also the neighbouring ones, as it is common to have aggregate buildings. Therefore, buildings within an urban centre do not react independently to the seismic action but, on the contrary, they are much influenced by the adjacent buildings. The structural interaction among neighbouring buildings under seismic action depends on factors such as: (1) the position of the building within the block; (2) the difference in height between the buildings; (3) the presence of staggered floors, or (4) the difference in the stiffness of adjacent bodies, whether due to different constructive systems, or due to differences in the amount of openings of the façades.
Therefore, alterations over time on the urban fabric may increase the vulnerability of the whole block. For example, the replacement of buildings with different constructive systems should have a significant influence. Firstly, because different stiffness of the bodies leads to different responses to the seismic action of neighbouring buildings, causing damage at the connecting points. In this respect, for instance, reinforced concrete buildings, adjacent to masonry dwellings, introduce a severe risk of hammering actions to take place. Secondly, it can also modify the relative position of the buildings within the block, changing the uniform reaction of the block. Besides, the enlargement and opening of new windows and doors changes the stiffness of the buildings, and ultimately affects the whole block seismic response. The description of these alterations of vernacular buildings inside aggregates located in historical urban centres is addressed in this paper, selecting the city of Vila Real de Santo António as a case study.

The reconstruction of Lisbon after the 1755's earthquake was not an isolated phenomenon, and other contemporary developments took place following similar plans, and proposing similar urban, architectural and construction solutions. Vila Real de Santo António was a completely new planned town, erected at the end of the 18th Century, following a Pombaline plan and thus, sharing many characteristics with Lisbon, such as the inclusion of seismic-resistant measures at an urban and architectural level. The urban plan consists of an extremely regular rectangular grid, organised around a large central square, along the riverfront, and with strictly defined architectural building types. 
It is a representative example of how an original rigorously designed plan, which took into consideration seismic-resistant provisions, has been continuously modified by anonymous and customary forces, without any principled changes, leading to the current unplanned spontaneous occupation and alteration of the urban layout. Most of the original buildings were substituted, or highly altered, and few buildings still preserve their original characteristics in terms of volume, construction characteristics, and opening distribution in elevation.

Because of this, Vila Real de Santo António was selected as a case study. Nevertheless, it fulfils another two main requirements: (i) it is located in the region of the Algarve, the southernmost area of Portugal mainland, which has a significant seismicity, and thus, it is prone to have developed a Local Seismic Culture; and (ii) traditional seismic strengthening solutions were already identified in the city, such as ties and, more specifically, frontal walls, which were one of the seismic-resistant provisions considered at the time of the erection of the city.

\section{IDENTIFICATION OF POSSIBLE SEISMIC VULNERABILITY ASSESSMENT METHODOLOGIES - AN OVERVIEW}

The seismic risk of a structure is determined by the combination of the seismic hazard, i.e. the probability of exceedance of a certain level of seismic activity of a certain intensity, and structural vulnerability. In some cases, other concepts such as the exposition of the elements at risk, involving factors like the density of the population, time of the day of the earthquake occurrence, and cost may be taken into account, when evaluating the risk. Since the seismic hazard is unavoidable, efforts should be placed on the assessment of seismic vulnerability, and on the subsequent reducing of the structural vulnerability, by the implementation of seismic strengthening strategies, in order to attain a reduced seismic risk.

The main objective of seismic vulnerability assessment methodologies is to measure and to predict the probability of reaching a given level of damage, in a given building, for a specific earthquake, and to estimate future losses (Calvi et al. 2006). However, they are able of identifying building fragilities, addressing an essential aspect, in which engineering research can intervene (Vicente et al. 2011), since the evaluation of the seismic vulnerability of existing constructions can be used to evaluate the need of retrofitting solutions, and to assess the efficiency in reducing the seismic vulnerability of proposed structural interventions.

Among the big variety of methodologies proposed by different authors, vulnerability index evaluation methods (Benedetti \& Petrini 1984) are based on post-earthquake damage observation and survey data, focusing on the identification and evaluation of constructive aspects and materials that are more influent in the seismic response of the building. Qualitative and quantitative parameters are thus defined, and a vulnerability index is calculated, as the weighted sum of these parameters, classifying the building according to their vulnerability. This index can be used to estimate structural damage after correlation to a specified seismic intensity, supported by post-earthquake recordings and statistical studies. They constitute a reliable large-scale assessment and have been extensively applied in Italy (GNDT 1994), and were recently implemented for the seismic vulnerability assessment of Portuguese masonry structures in several historical city centres (Vicente et al. 2011; Neves et al. 2012; Ferreira et al. 2013), obtaining useful and reliable results, as a first level approach.

The parameters used in this type of methodologies that seem to be more decisive in terms of seismic vulnerability are similar, including construction aspects such as: (a) the presence and effectiveness of the connection between orthogonal walls; (b) the ultimate shear strength of the vertical elements, which manly takes into account the distribution of the structural walls and the area of resisting walls in each orthogonal direction; (c) type and quality of the masonry, which in the case of masonry buildings accounts for material properties, masonry arrangement, size of units or presence of mortar; (d) plan regularity and configuration; (e) efficiency of the connections of the walls to horizontal diaphragms and roofs; (f) roof typology, weight and thrust; (g) number of floors and floor height; (h) the type of foundations; (i) number and location of wall openings; (j) the previous damage, alterations and conservation state. Classes of vulnerability are associated to each parameter, as well as weights, which reflect the relative importance of each one of them on computing the vulnerability index that characterizes the seismic behaviour of a masonry building.

When characterising existing urban centres new challenges raise, as it involves buildings, which do not behave independently, but are structurally connected to the adjacent ones, and are the result of a progressive growth of the cities, eventually resulting in complex structural units continuously modified, with no specific constructive rules. They are commonly known as building aggregates, and their study implies taking into account new specific parameters (Vicente et al. 2011; Formisano et al. 2011; Cardani et al. 2015), which can include: (i) the position of the building within the aggregate; (ii) the relative height of the building within the aggregate; (iii) the presence of staggered floors; (iv) the typological heterogeneity among adjacent units; or (v) the percentage difference of opening areas among adjacent façades.

Nevertheless, identifying building fragilities and obtaining accurate knowledge of the building characteristics, and the specific local structural and constructive features that this type of methodologies requires, can only be obtained through detailed building-bybuilding inspection (Santos et al. 2013, Maio et al. 2015). 


\section{ANALYSIS OF VILA REAL DE SANTO ANTÓNIO URBAN CENTRE}

Alterations on the urban fabric, such as the ones previously described, affect directly all the cited vulnerability parameters. Addressing the selected case of Vila Real de Santo António, the seismic vulnerability of the buildings has most likely been modified. In order to evaluate the effect of these alterations of the urban fabric on the seismic vulnerability of the constructions, a representative block was selected for a deeper analysis, including its constructive characterisation. Its structural history was also analysed, performing a comparison between original and current condition.

\subsection{The urban plan}

The distinctive feature of Vila Real de Santo António is the fact that it was born as a desire to design a city from scratch. It was an isolated sudden event, and not a transformation process with a continuation in time. The main reason for planning an entire new city was the attempt to boost the Algarve local economy through industrial development, and tighter tax. and customs controls (Mascarenhas 1996). This region was practically abandoned at the time, and much affected by the 1755 's earthquake, but was viewed as having a considerable economic potential, and an official recovery program was enacted during the 1760 s and 1770 s by the Marquis of Pombal. The program included taxes on imports, the establishment of artisan-based industries, agricultural marketing reforms and, the setting-up of a new town: Vila Real de Santo António (Chester \& Chester 2010). Because of its strategic position, at the extreme south of the Algarve, facing the Spanish border, it was created for the control of port transactions, and as a display of political power (Correia 1997).

The construction of Vila Real started in 1773, following the design of Reinaldo Manuel dos Santos, and it was finished in just a few months, using pre-fabricated and standardisation techniques and processes, applied also for the reconstruction of Lisbon (Chester \& Chester 2010). The plan was also based on the ideas and criteria already applied in Lisbon, resulting in a similar urban design in terms of composition and rigorous geometric clarity, as well as in the social and industrial functionality. Moreover, it also included some of the seismic-resistant measures used in Lisbon, such as the use of the characteristic timber frame wall, known as frontal walls. Given these facts, the Pombaline design plan of Vila Real de Santo António is a unique exceptional case, worthy of preservation as cultural heritage.

The Pombaline city plan is formed by a rectangular area, with one of the long sides placed along the river, facing east, and consisting of a grid of seven by six urban blocks (Fig. 1). The grid is organised around the big central square, and oriented along the river, north to south direction. The buildings situated in the river front are composed as a sort of façade for the city, with the Alfândega or Customs House occupying the central
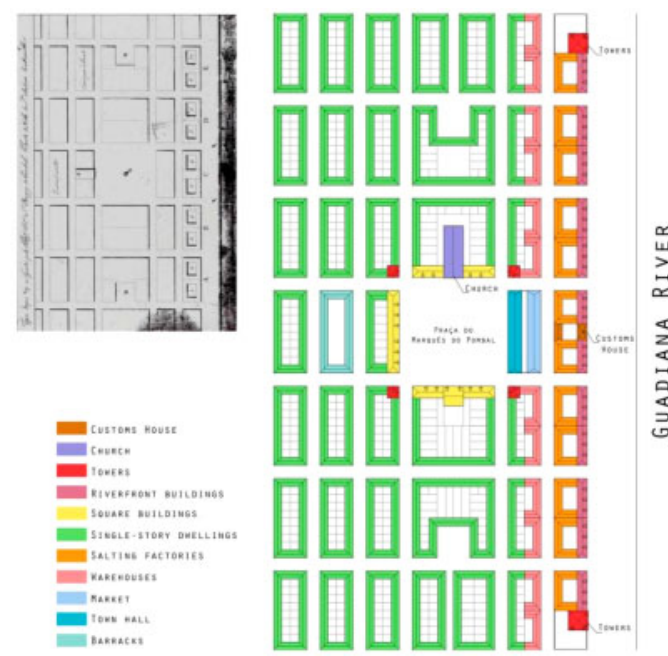

Figure 1. (left) first plan of the new city dating 1774 (Correia 1997); (right) Original plan of Vila Real de Santo António and main building types (credits: J. Ortega adapted from Rossa, 2009).

space, and two differentiated buildings at the edges, slightly higher than the rest, looking like two towers. The blocks are approximately $53 \mathrm{~m}$ long, and around $22 \mathrm{~m}$ wide, with the exception of the central one, which is slightly longer, approximately $55 \mathrm{~m}$. The other significant urban element is the main square, each side of it being defined by one block of approximately $55 \mathrm{~m}$ long, and two streets of around $9 \mathrm{~m}$ wide. The façades of these four sides are exactly the same, with the exception of the North one, where the main church is located. Apart from the buildings situated along the river front and surrounding the main square, which have two stories, the rest of the town was occupied by single storey houses. The whole plan is characterised by its strong regularity, and also the streets have all the same width.

\subsection{The building typologies}

There are essentially four distinct architectural types that defined a clear hierarchy, at an urban level, and there are some unique buildings that break the rigid scheme in specific points, which are the Customs House, the church and the 'towers'. The four building types are: (a) buildings in the river front, which have two main stories, and a third attic floor with dormer windows; (b) buildings in the main square, which also have two main stories; (c) single story dwellings, which in turn present several different types, but all of them are characterised by their small scale and extreme simplicity; and (d) single storey salting factories and warehouses behind the buildings in the river front, which basically consist of a system of masonry arcades, perpendicular to the façade walls, organised around a patio. Figure 1 shows the different architectural types devised within the original urban plan. 

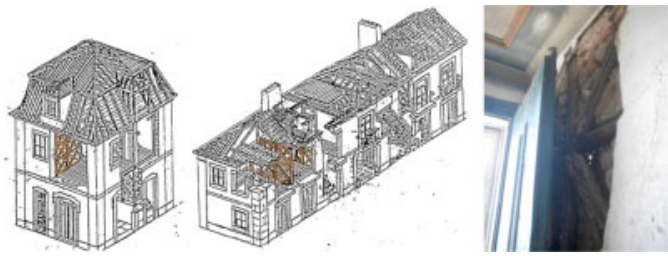

Figure 2. (left and middle) Use of frontal walls in two-story buildings in Vila Real de Santo António (Mascarenhas 1996); (right) Frontais preserved until today (Barros, 2011).

In terms of construction and materials, it should be firstly noted that the standardisation and prefabrication process, already applied for the Lisbon reconstruction plan, was used in the construction of Vila Real de Santo António. For example, the ashlars used for the quoins, plinths, opening lintels, steps or pilasters arrived already cut and worked, ready to be placed, as well as the wooden components, such as doors, windows, beams and floorboards (Correia 1997). Stone was transported by boat from neighbouring quarries, and it was used for the load bearing exterior and party masonry walls that are the main structural resisting element in all the buildings. Timber was used for the roof rafters and trusses, the floor beams and the timber frame partition walls of the upper floors. The timber roof structure was simply covered by wooden boards, on which ceramic tiles were laid. Sometimes reeds were also applied, intended to insulate the houses. Some ground floor rooms had vaulted ceilings, supporting the first floor, as a fire prevention measure, as it was done in Lisbon (Mascarenhas 1996). Ground floor partition walls were usually built in solid brick masonry. The buildings were finally plastered with lime and sand, and whitewashed. The construction of solid stone masonry building foundations using good quality lime mortar is an illustrative example of the generalised good quality and strength of the original buildings of Vila Real de Santo António (Oliveira 2009).

With respect to the seismic-resistant measures integrated in the buildings at the time of their construction, the most significant element was the incorporation of timber frame walls in the upper floors of the two-storey buildings, similar to those used in the Pombaline quarter in Lisbon. Given the low height of the buildings, the use of the whole seismic-resistant construction system developed for the reconstruction of Lisbon, known as gaiola, was not necessary. Nevertheless, the timber roof structure, and the timber floor structure were connected through these timber frame partition walls, known also as frontal walls (Correia 1997). These walls consisted of vertical, horizontal and diagonal timber members, filled with light masonry and they can still be observed in some of the buildings at the present (Fig. 2). The structure of the single storey dwellings simply consisted of load bearing stone masonry walls, and brick masonry partition walls. The roof was composed by timber rafters tied by collars, resting directly on the walls, and there

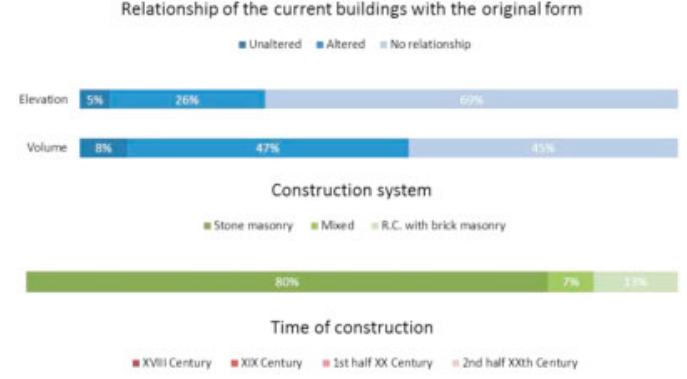

Figure 3. Characterization of the buildings in the Pombaline core of Vila Real de Santo António in relation with their original design (credits: J. Ortega adapted from Gonçalves, 2005).

was no ceiling. This simplicity and their regularity in plan and volume, together with their symmetry and small dimensions, only $2.7 \mathrm{~m}$ wall height, is enough for the buildings to have a significant resistance to earthquakes. Of course that the performance of these buildings to seismic action depends also on the quality of the connection between walls, as this is an important factor influencing the out-of-plane resistance.

\subsection{The current state of the Pombaline core of Vila Real de Santo António}

There has been a transformation process of the city, and the works carried out in the Pombalino core have led to an important depravation of their original characteristics. A previous important work was conducted aiming at analysing the transformation of the 1773 Pombalino core, within the Plano de Pormenor de Salvaguarda do Núcleo Pombalino de Vila Real de Santo António (SGU 2008). The work consisted of an analysis carried out on a building, intended to identify the remaining original Pombalino buildings and their morphological relationship with respect to the original design. Results indicated that only 155-164 buildings still possess Pombalino characteristics, illustrating the important alterations done in the historical built-up fabric, and the big degradation of the ideally original designed plan. Moreover, even the best preserved buildings still show important alterations in relation to their original form (Fig. 3). Generally, the transformation process has been characterized by a massive occupation of the blocks, leading to an extreme densification of the urban fabric, since patios were continuously occupied by additional constructions (Fig. 4).

Two-storey buildings located in the river front and the main square, together with the most significant buildings, present few alterations and preserve better their original design. On the contrary, the ordinary built-up fabric has considerably been more vulnerable to alterations. Thus, single storey buildings, both dwellings and salting factories, and warehouses, have been systematically exposed to demolitions, substitutions and large modifications, such as the addition 

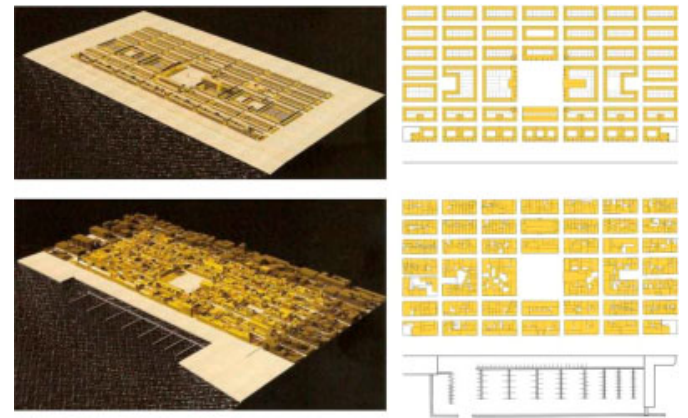

Figure 4. Comparison between the original plan and the current state of Vila Real de Santo António: (left) 3D model view (Gonçalves, 2009); (right) plan (credits: J. Ortega).

of new floors. This has also resulted in a significant increase in the average height of the buildings of the city.

The main alterations that can be found in the original constructions of the Pombalino core of Vila Real de Santo António involve the volume and the elevation. With respect to the volume, buildings were usually altered by the addition of new floors, or by the change of the eaves line. Regarding the elevation, modifications, these commonly consisted of the opening of new windows and doors, and the enlargement of the original openings. Other important common alteration reported, by the previously commented study has, been the substitution of the original roof typology, usually consisting of the replacement of the original hip roofs with flat ones (SGU 2008). Modifications of the construction system and structural elements, such as floors, can also be expected in most of the constructions. Most of these alterations are a normal consequence, resulting from the changes of the use of the buildings and the new needs of the users. Figure 5 shows some examples of the deep changes on the built-up environment, which have taken place during the last century in Vila Real de Santo António. With respect to the identification of traditional strengthening solutions, ties were usually observed in some buildings.

3.3.1 Detailed study of the original Alfândega block The block that occupies the central position in the river front and contains the Alfândega or Customs House (Fig. 1) was selected for a more detailed study about the qualitative evaluation of the influence and of the alteration seen in the seismic vulnerability of the block building.

The Customs House is one of the most important buildings of the city, as the symbol of the Pombalino political power, and because of displaying an important economical role in the region. One of the main reasons for choosing this block is the fact that some of the buildings within it still preserve the original qualities in terms of dimensions, architectural layout, and constructions solutions and materials, namely the

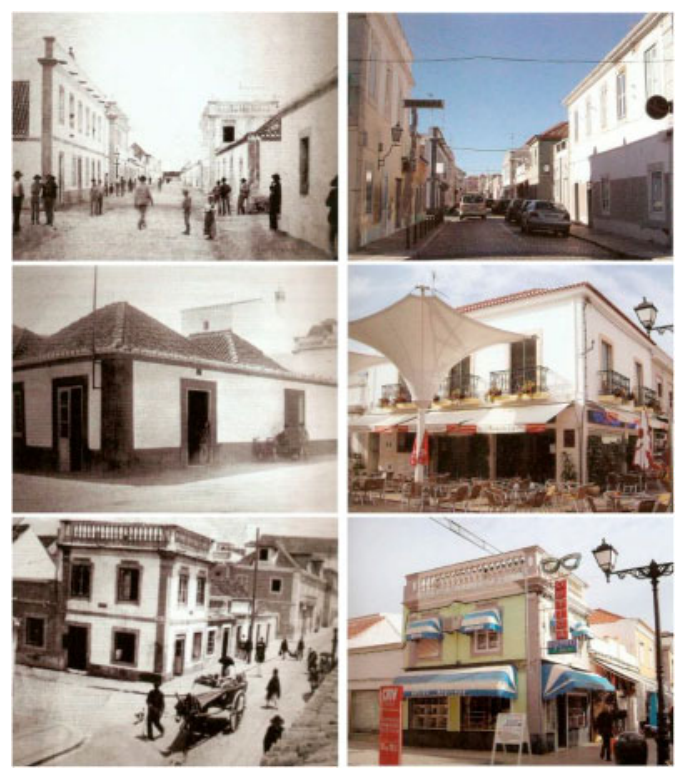

Figure 5. Examples of alterations of the original constructions occurred mainly during the XXth century (Gonçalves, 2009).

Customs House, and the two-storey buildings facing the river.

Besides the Customs House, which is a unique building within the city, the selected block included two of the previously described architectural typologies: the salting factories, and the river front buildings. Figure 6 shows the original block plans, the elevations and general dimensions. The composition of the block was very regular. Buildings facing the river front had two stories plus an attic floor, while the single story salting factories were situated behind them, forming a patio with a U-shape plan configuration. The Customs House was composed by two independent two-story buildings. The main one was located at the riverside, aligned with the river front buildings, and had a mansard roof that rises up from the roof ridgeline of the neighbouring buildings. The other building was placed at the back of the block, and was also higher than the adjacent single story salting factories. There was a third patio in-between these two buildings.

The roof structure of the river front buildings consisted of simple roof timber trusses, covered by wooden boards (Mascarenhas 1996). The mansard roof of the Customs House was also built using a timber frame, but the structure is more complex (Fig. 2). The roof structure of the single story factories simply consisted of a couple of rafters resting directly on the masonry walls and timber joists, on top of which, wooden boards were placed, composing the ceiling (Fig. 7). Sometimes, instead of eaves, parapets were built along the edge of the roof, as an extension of the wall, for the finishing of the roof. Over the wooden boards of every building, regional ceramic tiles were laid. 


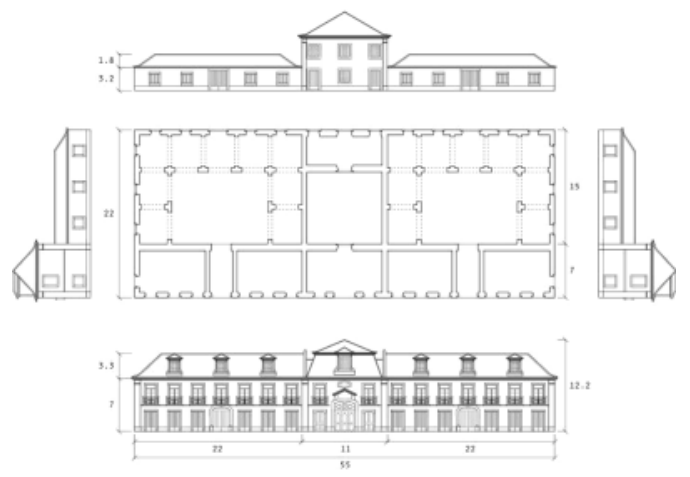

Figure 6. Original plans and elevation of the selected block (dimensions in meters) (credits: J. Ortega).

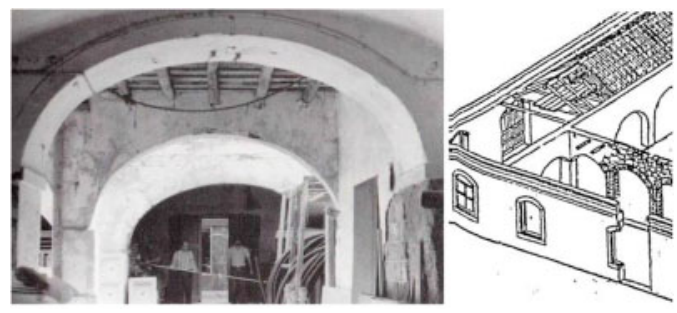

Figure 7. (left) system of arcades in the single story salting factories (Correia, 1997); (right) simple timber roof structure in the salting factories (Mascarenhas, 1996).

The floor structure of the river front buildings consisted also of timber beams and floorboards, being both elements pre-fabricated and imported from Lisbon, as previously commented. Assuming that the construction details were similar to those used in Lisbon, floor joists extended from one external wall to the other and their ends rested on transverse timber plates inserted within the walls, allowing a better distribution of stresses along the wall. The floorboards composing the flooring were placed perpendicular to the joists.

The timber frame partition walls of the upper floors in the river front buildings (Fig. 2) had also a structural function because, by connecting the different structural elements, i.e. roof, floor and exterior masonry walls, they contributed to the bracing of the building, improving its overall resistance. The partition walls at the ground floor level were heavier, built of solid brick masonry. The use of a lighter system in the upper level also helped to ensure a better structural behaviour, by lowering the centre of gravity of the building, and thus provide greater stability.

\subsection{Detailed study of the current Alfândega block}

The other main reason of choosing the Anfândega block is the fact that it is also a representative example of the transformation of the city. Some of the constructions within the block have suffered important alterations, some has been demolished and substituted and, at the same time, the block has been occupied by additional constructions. Figure 8 shows the constructive evolution of the case study, illustrated by a comparison between the original block and its current condition, while figure 9 shows some views of the current state of the building.

The river front buildings and, particularly, the Customs House are substantially less altered. They preserve most of their original characteristics in terms of elevation, but present some alterations in terms of volume, having some new constructions attached to the original building. On the other hand, the salting factories were either replaced with new buildings, or highly altered, mainly by addition of new floors. The original patios were also filled with new constructions and extensions of the original buildings.

All these alterations have increased the primary seismic vulnerability, because they affect directly most of the previously mentioned parameters that can be used to assess the seismic vulnerability of building aggregates. First of all, the original compact regular and rectangular plan configurations that typically behave better under seismic loading are completely modified. The accumulation of buildings within the patio has introduced setbacks and irregularities that may introduce torsional effects in the seismic response of the block.

This massive occupation of the patios, together with the addition of new floors to the original construction, has led to a significant increase in the height of the buildings within the block. The number of floors of a construction is already an important parameter that affects its vulnerability but the new buildings and additions do not respect the original eaves line, and introduce a big source of irregularity in elevation, leading to the presence of adjacent buildings with different heights, and thus increasing the seismic vulnerability. This type of alterations can also lead to the presence of staggered floors among the buildings within the block, which can be detrimental for the seismic response by introducing risk of hammering, particularly if the floors have been replaced with rigid reinforced concrete floors.

New buildings and alterations were built during the 19th and 20th centuries, but they were still built in stone masonry, which avoids the harmful effect that the typological heterogeneity between adjacent constructions can introduce. The original structure of the masonry arcades is, indeed, preserved in some of the old salting factories, and it can still be observed (Fig. 10 ), as well as some original vaults in the ground floor of the riverfront buildings. Roofs were mostly replaced or modified in every building, changing the original gable roofs for flat roofs (Fig. 10). The original eaves were also substituted by parapets, which are a non-structural element, more susceptible to topple.

Finally, there were many alterations in the original regular wall façade openings, both in their position, and the total area. The change in use of the buildings, and the commercial use of most of the ground floors of the buildings, led to the enlargement of the openings; and the opening of new ones, highly increasing 


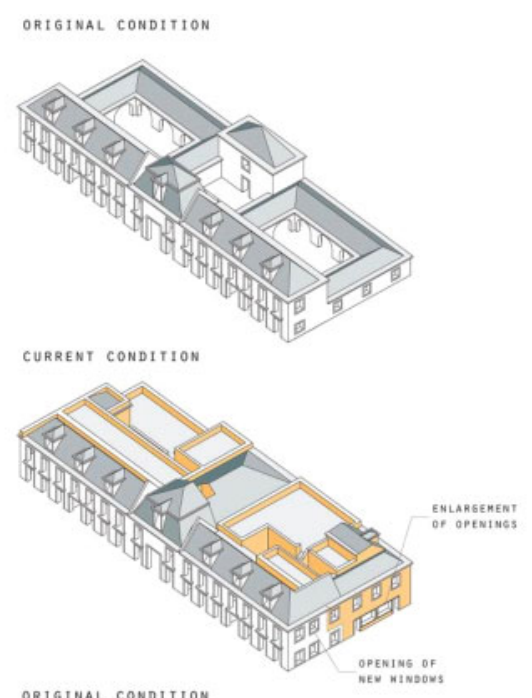

QRIGINAL CONDITION

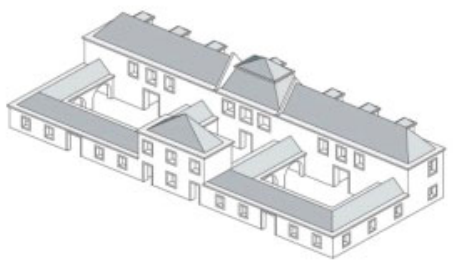

CURRENT CONDITION
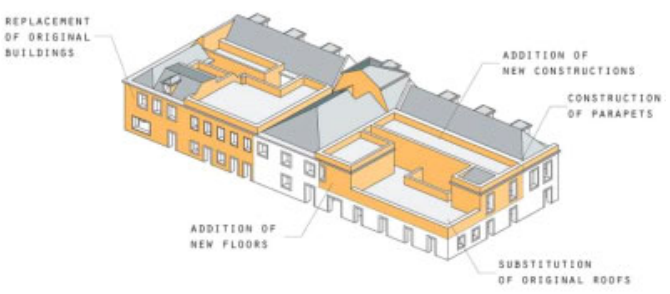

Figure 8. Comparison between the original and the current state of the block. The alterations are highlighted in orange (credits: J. Ortega).

the total area, and thus the overall vulnerability of the building. Other openings were changed in position, and some others were closed. The relative location of the openings and the alignment is crucial because of the change in the load path. Therefore, misaligned openings also increase the building's vulnerability. The fact that now some buildings within the block present a bigger number of openings than the adjacent ones, also cause a relative variation in the stiffness of neighbouring buildings, which is another parameter that may affect their seismic response.

\section{CONCLUSIONS}

The mischaracterisation of historical city centres is common everywhere. The particular case of Vila Real

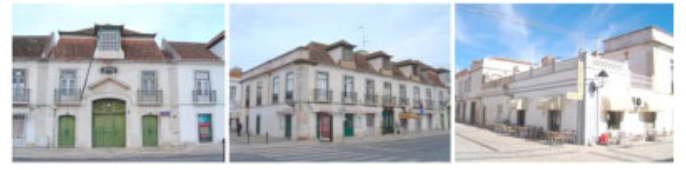

Figure 9. Views of the block (SGU 2008): (left) Customs House façade; (middle) river front buildings; (right) current state of the old salting factories (credits: J. Ortega).
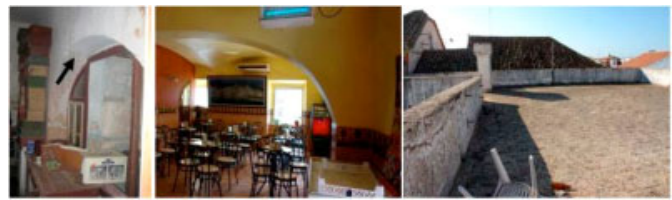

Figure 10. (left and middle) Remaining arches from the original salting factories (SGU, 2008); (right) commonly new flat roofs built replacing the originals (SGU, 2008).

de Santo António has been addressed, since it exemplifies how an originally strongly designed seismicresistant construction plan has been modified by successive transformations of the building form, resulting from new needs of the occupants. These alterations are not only detrimental in terms of loss of authenticity of an important architectural and urban heritage, but they also jeopardize the safety of the buildings, by affecting directly several parameters that are crucial in the seismic response of the building, and also introducing new sources of vulnerability.

The importance of assessing the seismic vulnerability of building aggregates in historical city centres lies precisely on this fact. Acknowledging that a deep characterisation of the constructions, including a comprehensive and detailing research on the geometry, structure, construction materials, not addressing just few critical parameters that can be recognised from outside, can provide an useful overview of how the seismic vulnerability of the studied block has increased notably, since its original condition, as it has been the objective of this study.

Vila Real de Santo António also exemplifies how the loss of the seismic awareness leads to the abandonment of Local Seismic Cultures. Here, the original seismic concern, arisen after the 1755's earthquake, resulted in an effective urban plan, and a carefully constructed architecture, which was eventually forgotten and compromised. Several reinforcement measures, at an urban level, such as reinforcing arches, buttresses or ties, can be commonly observed in other cities, where a Local Seismic Culture has been more active, because of the frequency of earthquakes, but these are missing in the case of Vila Real. The re-adoption of some of these traditional techniques can help reducing the seismic vulnerability of these constructions. 


\section{ACKOWLEDGEMENTS}

The work presented in this paper was supported financially by the research project Seismic V - Vernacular Seismic Culture in Portugal (PTDC/ATPAQI/3934/2012) funded by the National Foundation for Science and Technology.

\section{REFERENCES}

Barros, J.C. (2011). Núcleo Pombalino de Vila Real de Santo António: Salvaguarda, Desenvolvimento. VIII Congresso Internacional das Cidades e Entidades do Iluminismo, Vila Real de Santo António, Portugal.

Benedetti, D. \& Petrini, V. (1984). Sulla vulnerabilità di edifici in muratura: Proposta di un método di valutazione. L'Industria delle Costruzioni 149(1), 66-74.

Calvi, G.M., Pinho, R., Magenes, G., Bommer, J.J., RestrepoVélez, L.F. \& Crowley, H. (2006). Development of seismic vulnerability assessment methodologies over the past 30 years. ISET Journal of Earthquake Technology 34(472), 75-104.

Cardani, G., Giaimi, P., Bellucco \& P., Binda, L. (2015). A simplified method of analysis to define the seismic vulnerability of complex buildings in historic centres. In $12 \mathrm{th}$ North American Masonry Conference. Denver, Colorado, US.

Chester, D. \& Chester, O. (2010). The impact of eighteenth century earthquakes on the Algarve region, southern Portugal. Geographical Journal 176(4), 350-370.

Correia, J. (1997). Vila Real de Santo António. Urbanismo e Poder na Política Pombalina (PhD Thesis, Faculdade de Arquitectura da Universidade do Porto, Portugal).

Ferreira, T.M., Vicente, R., Mendes da Silva, J.R., Varum, H. \& Costa, A. (2013). Seismic vulnerability assessment of historical urban centres: case study of the old city centre in Seixal, Portugal. Bulletin of Earthquake Engineering 11(5), 1753-1773.

Formisano, A., Florio, G., Landolfo, R. \& Mazzolani, F.M. (2011). Numerical calibration of a simplified procedure for the seismic behaviour assessment of masonry buildings aggregates. In Proceedings of 13th Int. Conf. Civil Structural Environ. Eng. Comput. Stirlingshire, Scotland, UK.
GNDT (1994). Scheda di esposizione e vulnerabilità e di rilevamento danni di primo livello e secondo livello (muratura e cemento armato). Gruppo Nazionale per la Difesa dai Terremoti (GNDT). Rome, Italy.

Gonçalves, A. (2005). Caracterização do Núcleo Pombalino. InPlanos - Salvaguarda Vila Real de Sto António: núcleo pombalino, ECDJ.9. Universidade de Coimbra, Portugal.

Gonçalves, A. (2009). Vila Real de Santo António. Planeamento de pormenor e salvaguarda em desenvolvimento. Monumentos 30, 40-53.

Maio, R., Ferreira, T.M. \& Vicente, R. (2015). A morfologia dos núcleos urbanos antigos: levantamento arquitectónico e construtivo do Bairro Ribeirinho de Faro, Portugal. Conservar Património.

Mascarenhas, J.M.D. (1996). A study of the design and construction of buildings in the Pombaline quarter (PhD Thesis, University of Glamorgan, UK.

Neves, F., Costa, A., Vicente, R., Oliveira, C.S. \& Varum, H. (2012). Seismic vulnerability assessment and characterisation of the buildings on Faial Island, Azores. Bull Earthquake Eng 10(1), 27-44.

Oliveira, A. (2009). Casa da Câmara de Vila Real de Santo António. Levantamento arqueológico. Monumentos 30: 54-61.

Rossa, W. (2009). Cidades da razão: Vila Real de Santo António e arredores. Monumentos 30, 16-31.

Santos, C., Ferreira, T.M., Vicente, R. \& Mendes da Silva, J.R. (2013). Building typologies identification to support risk mitigation at the urban scale - Case study of the old city centre of Seixal, Portugal. Journal of Cultural Heritage 14(6), 449-463.

SGU (2008). Plano de Pormenor de Salvaguarda do Núcleo Pombalino de Vila Real de Santo António. Sociedade de Gestão Urbana de Vila Real de Santo António (SGU).

Vicente, R., Parodi, S., Lagomarsino, S., Varum, H. \& Mendes da Silva, J.R. (2011). Seismic vulnerability and risk assessment: case study of the historic city centre of Coimbra, Portugal. Bulletin of Earthquake Engineering 9(4), 1067-1096. 